\title{
Synaptic Properties of Corticocortical Connections between the Primary and Secondary Visual Cortical Areas in the Mouse
}

\author{
Roberto De Pasquale and S. Murray Sherman \\ Department of Neurobiology, University of Chicago, Chicago, Illinois 60637
}

\begin{abstract}
Despite the importance of corticocortical connections, few published studies have investigated the functional, synaptic properties of such connections in any species, because most studies have been purely anatomical or aimed at functional features other than synaptic properties. We recently published a study of synaptic properties of connections between the primary and secondary cortical auditory areas in brain slices from the mouse, and, in the present study, we aimed to extend this by performing analogous studies of the primary and secondary visual areas (V1 and V2). We found effectively the same results. That is, connections between V1 and V2 in both directions were quite similar; in each case, the glutamatergic inputs could be classified as one of two types, Class 1B (formerly "driver") and Class 2 (formerly "modulator"). There is a clear laminar correlation for these different inputs, in terms of both the laminae of origin and those in which the recorded cells were located. Our data suggest a common pattern to the functional organization of corticocortical connectivity in the mouse cortex.
\end{abstract}

\section{Introduction}

Corticocortical interactions are of obvious importance to the macroscopic functioning of cortex and constitute one of the principal systems of connections in the mammalian brain. The study of their functional organization is thus of particular interest. However, although the functional properties of corticocortical connections have primarily been investigated within a single area (Shao and Burkhalter, 1996; Fleidervish et al., 1998; Reyes et al., 1998; Atzori et al., 2001; Frick et al., 2007), the physiology of interactions between different areas has been essentially overlooked or limited to extracellular recordings that are unsuited to determine synaptic properties (Domenici et al., 1995; Nowak et al., 1997; Hishida et al., 2003). Indeed, the emphasis of most of the studies of connectivity between cortical areas has mostly been anatomical (Zeki, 1976; Zeki and Sandeman, 1976; Seltzer and Pandya, 1978; Rockland and Pandya, 1979; Zeki, 1980; Maunsell and van Essen, 1983; Shipp and Zeki, 1989; Coogan and Burkhalter, 1990; Felleman and Van Essen, 1991; Beck and Kaas, 1998a,b; Kaas and Collins, 2001; Wu and Kaas, 2003) with a limited contribution to the study of synaptic proprieties (Dong et al., 2004). Often, strength and significance have been equated with the number of inputs, based on the assumption that all pathways are

\footnotetext{
Received July 18, 2011; revised Sept. 2, 2011; accepted Sept. 8, 2011.

Author contributions: R.D. and S.M.S. designed research; R.D. performed research; R.D. and S.M.S. analyzed data; R.D. and S.M.S. wrote the paper.

This work was supported by National Institute on Deafness and Other Communication Disorders Grant DC008794 (S.M.S.). We thank Charles Lee for helping with histological samples.

The authors declare no competing financial interests.

Correspondence should be addressed to S. M. Sherman, Department of Neurobiology, University of Chicago, Abbott J-117, 947 E. 58th Street, Chicago, IL 60637. E-mail: msherman@bsd.uchicago.edu.

DOI:10.1523/JNEUROSCI.3664-11.2011

Copyright $\odot 2011$ the authors $\quad 0270-6474 / 11 / 3116494-13 \$ 15.00 / 0$
}

functionally homogeneous (Rockland and Pandya, 1979; Maunsell and van Essen, 1983; Shipp and Zeki, 1989; Coogan and Burkhalter, 1990; Felleman and Van Essen, 1991). However, a recent study of connections between auditory cortical areas in the mouse has not only demonstrated that these connections are heterogeneous but also that laminar correlates exist to the two functional classes of glutamatergic input described previously (Covic and Sherman, 2011). We sought to expand on these recent findings to determine how the laminar patterns seen in corticocortical connections in auditory cortex might extend to other cortical areas. Accordingly, we used an in vitro slice preparation from the mouse brain to characterize the synaptic properties involved in corticocortical connections between the primary (V1) and the secondary (V2) visual cortices.

\section{Materials and Methods}

Preparation and maintenance of slices

We adopted for this study procedures similar to those described previously from this laboratory (Reichova and Sherman, 2004; Lam and Sherman, 2005; Covic and Sherman, 2011). The protocols we followed were approved by the Institutional Animal Care and Use Committee of the University of Chicago. All experiments were performed on tissue slices taken from BALB/c mice of both sexes (10-19 d postnatal; Harlan). Each animal was deeply anesthetized by inhalation of isoflurane (AErrane; Baxter Pharmaceuticals). The brain was quickly removed and cooled $\left(0^{\circ} \mathrm{C}\right)$ in modified artificial CSF (ACSF) containing the following (in $\mathrm{mm}$ ): 206 sucrose, $25 \mathrm{NaHCO}_{3}, 2.5 \mathrm{KCl}, 10$ $\mathrm{MgSO}_{4} 1.25 \mathrm{NaH}_{2} \mathrm{PO}_{4}, 0.5 \mathrm{CaCl}_{2}$, and $11 \mathrm{D}$-glucose, oxygenated with carbogen $\left(5 \% \mathrm{CO}_{2}-95 \% \mathrm{O}_{2}\right)$. Slices $(\sim 500 \mu \mathrm{m}$ thick) were cut at a $25-30^{\circ}$ anterior tilt relative to the coronal plane and kept oxygenated in a holding chamber with $\mathrm{ACSF}_{\text {Normal }}$ (in mM: $125 \mathrm{NaCl}, 25$ $\mathrm{NaHCO}_{3}, 3 \mathrm{KCl}, 1.25 \mathrm{NaH}_{2} \mathrm{PO}_{4}, 1 \mathrm{MgCl}_{2}, 2 \mathrm{CaCl}_{2}$, and 25 D-glucose) for $1 \mathrm{~h}$ at room temperature $\left(\sim 25^{\circ} \mathrm{C}\right)$ before recording. 


\section{Electrophysiological recordings}

Slices were transferred to a submergent recording chamber and continually perfused with oxygenated ACSF $\mathrm{Normal}_{\text {. }}$. Whole-cell recordings were obtained from neurons from V2 and V1 in layers 2/3, 4, 5a, 5b, and 6. Recording pipettes were fabricated from borosilicate glass (Garner Glass) with input resistances of $\sim 6-10 \mathrm{M} \Omega$ and filled with intracellular solution containing the following (in $\mathrm{mm}$ ): $135 \mathrm{~K}$-gluconate, $7 \mathrm{NaCl}, 10 \mathrm{HEPES}$, $2 \mathrm{Na}_{2} \mathrm{ATP}, 0.3 \mathrm{Na}_{3} \mathrm{GTP}, 2 \mathrm{MgCl}_{2}, 0.5-1 \mathrm{~mm}$ dinitrostilbene-2,2' disulfonic acid (DNDS), pH 7.3 (0.1-0.5\% biocytin, $290 \mathrm{mOsm})$. All experiments were performed on a visualized slice setup under a differential interference contrast equipped Axioscop 2FS microscope (Carl Zeiss). Whole-cell recordings were made by using a Multiclamp 700B amplifier and pClamp software (Molecular Devices). Only cells with a stable access resistance of $<20 \mathrm{M} \Omega$ were recorded. Hyperpolarizing currents were injected to identify $I_{\mathrm{h}}$, whereas depolarizing currents were injected to identify regular, tonic, or bursting spike patterns.

Laser uncaging of glutamate. Identification of inputs connected to each recorded cell was accomplished by monitoring EPSCs following our previously described methods for uncaging of glutamate by photostimulation (Lam and Sherman, 2005; Covic and Sherman, 2011). Data acquisition and photostimulation were controlled by software written in Matlab (MathWorks). Nitroindolinyl-caged glutamate (Sigma-RBI; Canepari et al., 2001) was applied to recirculating ACSF $_{\text {Normal }}$ with a concentration of $0.37 \mathrm{~mm}$. During recording sessions, focal photolysis of caged glutamate was achieved by a pulsed UV laser ( $355 \mathrm{~nm}$ wavelength, frequency-tripled $\mathrm{Nd}: \mathrm{YVO}_{4}, 100 \mathrm{kHz}$ pulse repetition rate; DPSS Laser), to provide three 1-ms, 100-pulse light stimuli. Neutral density filters controlled the intensity of the stimulus. The laser beam had a $5 \mathrm{~mW}$ intensity, and its position was directed into the side port of the Axioscop 2FS microscope, controlled using a pair of mirror galvanometers (Cambridge Technology), and then focused onto the brain slice using a low numerical aperture (NA), low-magnification objective lens $(10 \times / 0.3$ $\mathrm{NA} /$ water UMPlanFl or $4 \times / 0.13 \mathrm{NA} /$ air UPlanFl; Olympus). Software controlled the angles of the galvanometers and thereby determined the position stimulated by the laser. The optics was designed to generate a nearly cylindrical beam in the slice to keep the mapping two dimensional. The Q-switch of the laser and a shutter (LS3-ZM2; Vincent Associates) controlled the timing of the laser pulse for stimulation. The beam expansion was limited to a twofold gain through the scan lens/tube lens pair. The narrow beam under-filled the objective and could be focused on a spot in the specimen plane that was $\sim 10 \mu \mathrm{m}$ in the $x-y$ dimension and larger $(\gg 100 \mu \mathrm{m})$ in the $z$-axis. Previous studies had shown that individual dendrites can be directly stimulated by glutamate uncaging at a lateral $(x-y)$ resolution of $\sim 15 \mu \mathrm{m}$ (Lam and Sherman, 2005).

Cells in V1 or V2 were patched and recorded in voltage clamp, and photostimulation was directed at regions of V2 or V1, respectively. Voltage traces were recorded and quantified during the $100 \mathrm{~ms}$ period after UV stimulus onset, using custom software. Photostimulation caused the laser uncaging of glutamate at specific locations of the brain slice. This allowed us to verify connectivity and localize the afferent source when the photostimulation evoked consistent responses in the patched cell. Monosynaptic connectivity was assumed when the evoked responses had a latency of $<3 \mathrm{~ms}$, latency jitter was of $<1 \mathrm{~ms}$, and reliably appeared with virtually no failures. With these criteria, we mapped out the afferent area to the patched cell, which we refer to as the "footprint"; we also determined the area from which the largest responses were evoked, which was always near the footprint center, and we referred to this as the "hotspot." All such maps were achieved using a preset stimulation grid designed to provide a sequence of stimulation that avoided the occurrence of short-term synaptic effects, such as receptor desensitization.

Synaptic physiology. Once a hotspot was mapped, we placed onto it a bipolar concentric electrode ( $125 \mu \mathrm{m}$ pole distance; FHC) to activate the identified pathway. Electrical stimulation consisted of $0.1-0.2 \mathrm{~ms}$ pulses and ranged from 10 to $130 \mathrm{~Hz}$. We included in our data only responses that we determined to be monosynaptic, which was reevaluated during electrical stimulation by having a latency $<3.5 \mathrm{~ms}$, a latency jitter of $<1$ $\mathrm{ms}$, and no failures for stimulation levels above threshold. In all cases, inputs deemed to be monosynaptic from photostimulation were also deemed monosynaptic to electrical stimulation. Most synaptic proper-
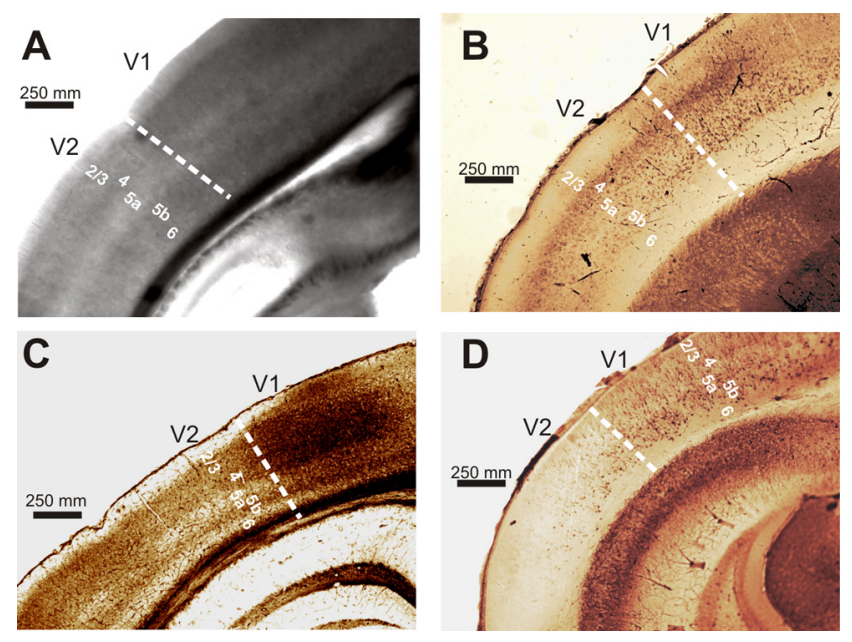

Figure 1. Identification of visual cortical areas in the mouse. $\boldsymbol{A}$, Differential interference contrast image of living slice preparation during a recording session. In V1, layer 4 and layer $5 \mathrm{~b}$ have higher cell packing densities compared with V2. Layer 1 is thin and aneuronal. We did not distinguish layer 2 from layer 3 and refer to these as "layers 2/3"; these lie directly above the dense packing of cells in layer 4. Layer 5 a is more sparsely packed with cells than is layer 4. Layer $5 b$ shows an increase in cell packing density, and layer 6 has a lower cell packing density than layer $5 \mathrm{~b}$. $\boldsymbol{B}$, Example of a brain section immunostained with an antibody to the type $2 / 3 \mathrm{mGluR}$. C, Example of a brain section stained for cytochrome oxidase. D, Example of brain section immunostained with an antibody to parvalbumin.

ties were based on "minimal stimulation," which is defined as follows: the stimulation level was increased from subthreshold in $5 \mathrm{~mA}$ steps until a reliable response was triggered, intensity was then further increased by 5 $\mathrm{mA}$ from this point, and this was the level of minimal stimulation. Only for experiments aimed at determining the relationship between stimulation intensity and evoked EPSP amplitude were higher stimulation levels used.

The application of $\mathrm{GABA}_{\mathrm{A}}$ antagonists was necessary to isolate glutamatergic synapses to properly study paired-pulse effects, because the recruiting of postsynaptic GABA responses could make glutamatergic facilitating responses appear to be depressing. The complete blockade of inhibition by bath application of $\mathrm{GABA}_{\mathrm{A}}$ antagonists generally induces a hyperexcitable situation that causes paroxysmal activity in cortical neurons. These problems were overcome by the use of the $\mathrm{GABA}_{\mathrm{A}}$ antagonist dinitrostilbene-2,2' -disulfonic acid (DNDS), a chloride channel blocker,

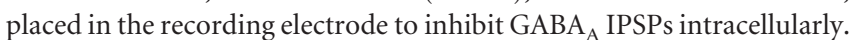
This antagonist diffuses from the recording electrode directly into the postsynaptic cell, restricting the blockade of inhibition to the single recorded neuron (Dudek and Friedlander, 1996; Covic and Sherman, 2011).

Single pulses or low-frequency stimulation are sufficient to activate ionotropic glutamate receptors (iGluRs). Activation of metabotropic glutamate receptors (mGluRs), however, usually requires relatively high-frequency stimulation (HFS, $130 \mathrm{~Hz}$ ) (McCormick and von Krosigk, 1992; Wu et al., 2001). The isolation of mGluR responses was achieved delivering HFS in the presence of iGluR antagonists (50 $\mu \mathrm{M}$ DNQX for AMPA receptors and 40 $\mu \mathrm{M}$ MK-801 for NMDA receptors). Once the presence of an mGluR response component was established, specific antagonists were then applied to determine the receptor subtypes involved as follows. We used the antagonist LY367385 [( S)-(+)-amino-4-carboxy-2-methylbenzeneacetic acid] (40 $\mu \mathrm{M})$ to identify type $1 \mathrm{mGluRs}$ (mGluR1s), the antagonist MCCG [( $S)-2$ amino-2-methyl-4-phosphonobutanoic acid] (50 $\mu \mathrm{M})$ to identify Group II mGluRs (including types 2 and 3 that we did not distinguish and refer to as mGluR2/3s), and the antagonist MPEP [2-methyl-6-(phenylethynyl)pyridine hydrochloride] ( $50 \mu \mathrm{M}$ ) to identify type 5 mGluRs (mGluR5s). To test whether evoked mGluR responses were present postsynaptically, the general mGluR agonist, ACPD [( \pm -1-aminocyclopentane-trans-1,3-dicarboxylic acid] was bath applied $(100 \mu \mathrm{M})$ after blocking synaptic activity with a preparation of iGluR antagonists and low- $\mathrm{Ca}^{2+}(0.2 \mathrm{~mm}) /$ high- $\mathrm{Mg}^{2+}(6 \mathrm{mM})$ $\mathrm{ACSF}_{\text {Normal }}$. Agonist and antagonist solutions were prepared in dis- 
tilled water or DMSO according to the solubility features of the chemical. Pharmacological agents were diluted to their final concentration and added to ACSF $_{\text {Normal }}$ buffer. The buffer was then delivered to the recording chamber through the use of a motorized peristaltic pump in a recirculating mode. The ultimate bath concentration was calculated to be onefourth of the initial concentration according to the chamber volume and the rate of perfusion. Any stimulation protocol was performed only after a minimum of $5 \mathrm{~min}$ after initial bath application. The choice of agonists, antagonists, and concentrations was based on the efficacy already tested in characterizing corticothalamic and thalamocortical inputs in the mouse somatosensory and auditory systems (Reichova and Sherman, 2004; Lee and Sherman, 2008; Covic and Sherman, 2011).

\section{Results}

Visual cortical areas V1 and V2 and the different layers noted below were identified by differential interference contrast microscopy before each recording experiment. V1 showed a higher cell body density than did V2, and different packing densities also served to demarcate cortical layers (Fig. 1A). The same pattern was observed in coronal sections immunostained with an antibody to mGluR2/3 (Fig. $1 B$ ), after cytochrome oxidase staining (Fig. $1 C$ ), or immunostained with an antibody to parvalbumin (Fig. $1 D$ ). Layer 1 appeared thin and aneuronal. Layer 4 was identified by its dense packing of cell bodies. We did not distinguish layer 2 from layer 3 but treated them as a single layer, referred to as "layers $2 / 3$ "; this was found between layers 1 and 4 . Layer $5 \mathrm{~b}$ was also identified by its high cell packing density, and so layer 5a was recognized as lying between layers 4 and 5b. Layer 6 had a lower cell packing density than layer $5 \mathrm{~b}$ and was located between that layer and the white matter.

We recorded from 267 neurons in V1 and V2, and for each we used laser uncaging of glutamate (referred to hereafter as "photostimulation"; Callaway and Katz, 1993; Lam and Sherman, 2005) to map the region in the afferent area in which afferent cell bodies were located as described in Materials and Methods. Among these, only 121 could be activated from the other cortical area by photostimulation, and only these 121 are considered further, 61 in V2 activated from V1 and 60 in V1 activated from V2. These cells were located in all of layers $2 / 3$ through 6. Cells of V2 had resting membrane potentials of $-64.2 \pm 1.8 \mathrm{mV}$ and input resistances of $279.2 \pm 106.3 \mathrm{M} \Omega$. The respective values for our population of $\mathrm{V} 1$ cells were $-63.1 \pm 4.45 \mathrm{mV}$ and $05.7 \pm 134.1 \mathrm{M} \Omega$. Current injections were applied to 103 of the 121 neurons, and all showed a regular spiking pattern. A subgroup of 20 cells were successfully filled with biocytin; 17 exhibited pyramidal morphology and 3 exhibited stellate morphology. In both cortices, the pyramidal cells were found in all layers, whereas the stellate cells were found only in layer 4 .

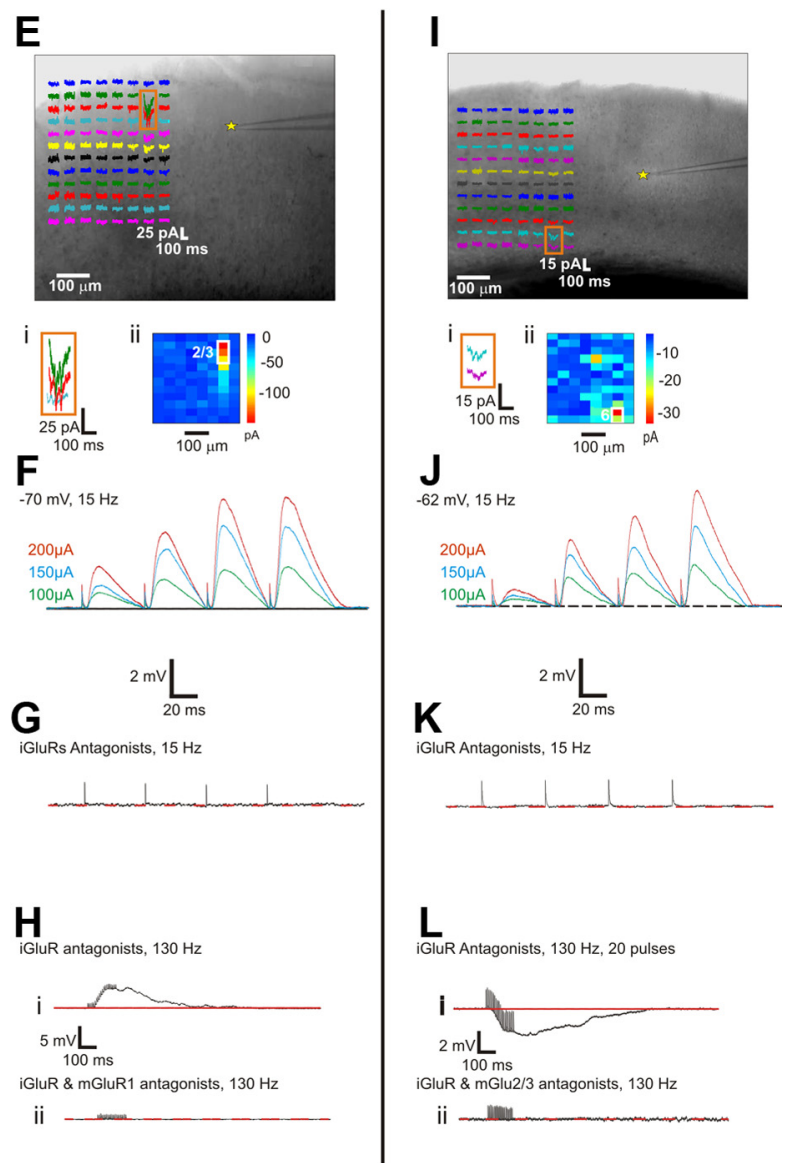

Figure 2. Response examples in the V1-to-V2 pathway. $A-D$, Example of a Class $1 B$ response with recorded cell in layer 4 of V2 star. The footprint and hotspot region is enlarged in $\boldsymbol{A} \boldsymbol{i}$ and shown in false color in Aii. B, Stimulation in the hotspot elicits paired-pulse depression and a graded response. $\boldsymbol{C}$, The response is blocked by iGluR antagonists at a stimulation rate of $15 \mathrm{~Hz}$. $\boldsymbol{D}$, response with is hyperpolarizing (Li) and blocked by mGluR2/3 antagonist (Lii).

Photostimulation (i.e., uncaging of glutamate) was performed to determine the monosynaptic afferent zones, the footprints, and hotspots (see Materials and Methods and Fig. $2 A, E, I$ ). In each case, successful photostimulation confirmed the presence of an afferent pathway from the footprint area to the recorded cell, because photostimulation activates only cell bodies and dendrites, not axons. We then placed concentric, bipolar stimulating electrodes over the hotspot and evoked EPSPs (or EPSCs) from activating the hotspot electrically via these electrodes for additional data collection.

\section{Terminology}

As documented below, all afferent inputs between V1 and V2 in both directions could be identified as a member of one of two classes, which we have described previously and call Class $1 \mathrm{~B}$ and Class 2 (Covic and Sherman, 2011). This classification of glutamatergic pathways was originally made in thalamus and called Driver (later changed to Class 1) and Modulator (later changed to Class 2; Sherman and Guillery, 1998, 2006; Covic and Sherman, 2011; Viaene et al., 2011a). However, one of the parameters used to distinguish these classes, namely the relationship of evoked 
EPSP amplitude to stimulus intensity, was found to be quite different between responses that otherwise seemed to belong to the Class 1 group. That is, Class 1 responses innervating thalamic relay cells and those of thalamocortical inputs to layer 4 showed an all-or-none response profile (Reichova and Sherman, 2004; Lee and Sherman, 2008, 2010; Petrof and Sherman, 2009; Viaene et al., 2011a), whereas those shown by cortical cells to intracortical stimulation often showed a graded response profile (Covic and Sherman, 2011). We have thus adopted the terminology of Class 1A for Class 1 responses showing an all-or-none response profile and Class 1B for those showing a graded profile.

\section{The V1-to-V2 pathway}

Data for the V1-to-V2 pathway were obtained from 23 cells in V2 responding to activation of its $\mathrm{V} 1$ hotspot with Class $1 \mathrm{~B}$ responses and 38 with Class 2 responses.

\section{Glutamatergic response classes}

A Class $1 \mathrm{~B}$ response is illustrated in Figure $2 A-D$, which shows a cell recorded in layer 4 of $\mathrm{V} 2$ with responses evoked by stimulating layer 4 of V1. Electrical stimulation at $15 \mathrm{~Hz}$ elicited pairedpulse depression, meaning that a train of stimuli evoked an initially large-amplitude EPSP, followed by EPSPs of progressively smaller amplitudes (Fig. 2B). At this $15 \mathrm{~Hz}$ stimulation rate, the evoked EPSPs were blocked by application of iGluR antagonists (Fig. 2C). To detect the possible presence of mGluRs, we applied HFS (130 Hz; McCormick and von Krosigk, 1992; Wu et al., 2001, 2008) with the iGluR blockers present and found no evidence for an mGluR response component (Fig. 2D).

A Class 2 response is illustrated in Figure $2 E-H$, which shows a cell recorded in layers $2 / 3$ of $\mathrm{V} 2$ with responses evoked by stimulating layers $2 / 3$ of V1. Here, electrical stimulation at $15 \mathrm{~Hz}$ evoked a pattern of paired-pulse facilitation, meaning that the first EPSP was relatively small but subsequent ones were progressively larger (Fig. $2 F$ ). While stimulating at $15 \mathrm{~Hz}$, EPSPs were completely blocked by iGluR antagonists (Fig. 2G), but HFS in the presence of iGluR blockers evoked a long slow depolarization corresponding to an mGluR1 response (Fig. $2 H$ ). In some Class 2 responses, HFS evoked a hyperpolarizing effect attributable to mGluR2/3 activation (Fig. $2 I-L$ ).

Note that both response classes have a graded response profile, meaning that increasing stimulus intensity evokes increasingly large EPSPs (Fig. $2 B, F, J$ ), and this is further documented below.

\section{Population data}

Figure $3 A$ shows a three-dimensional scatter plot of parameters for the recorded cells showing clear clustering into two groups corresponding to Classes $1 \mathrm{~B}$ and 2 , thereby confirming our classification scheme. The three parameters plotted here are as follows: the paired-pulse ratio, which is the amplitude of the second EPSP evoked divided by the first; the amplitude of the first EPSP evoked at minimal stimulation intensity; and the extent of the mGluR response, which is the maximum voltage change evoked (either depolarizing for mGluR1 and/or mGluR5 activation, or hyperpolarizing for mGluR2/3 activation) in the $300 \mathrm{~ms}$ period after HFS while iGluR antagonists are present. The paired-pulse ratio was lower for Class $1 \mathrm{~B}$ inputs $(0.615 \pm 0.036$ vs $1.950 \pm 0.138, p<0.0001, t$ test $)$, the amplitude of the first EPSP evoked was greater for Class $1 \mathrm{~B}$ inputs $(2.153 \pm 0.307$ vs $0.684 \pm 0.069, p<0.0001, t$ test $)$, and the amplitude of the mGluR response was greater for Class 2 inputs ( $3.584 \pm 0.377$ vs $0.256 \pm 0.024, p<0.0001, t$ test).

Because short-term plasticity (i.e., paired-pulse effects) is a key parameter that distinguishes Class $1 \mathrm{~B}$ from Class 2, we inves-

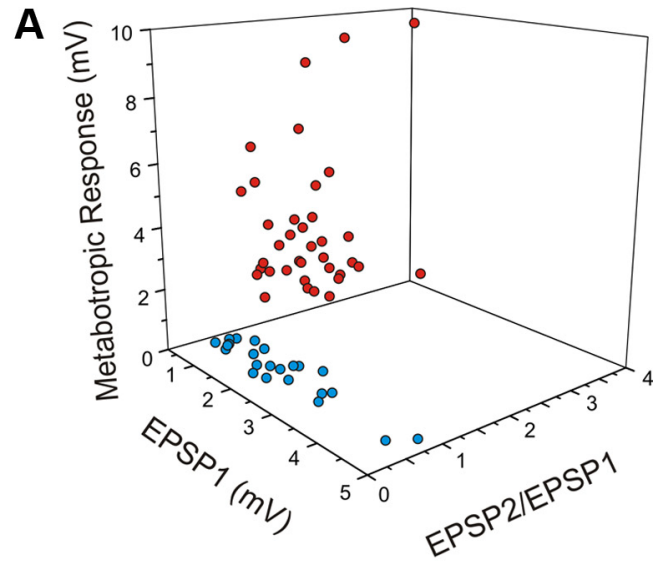

B
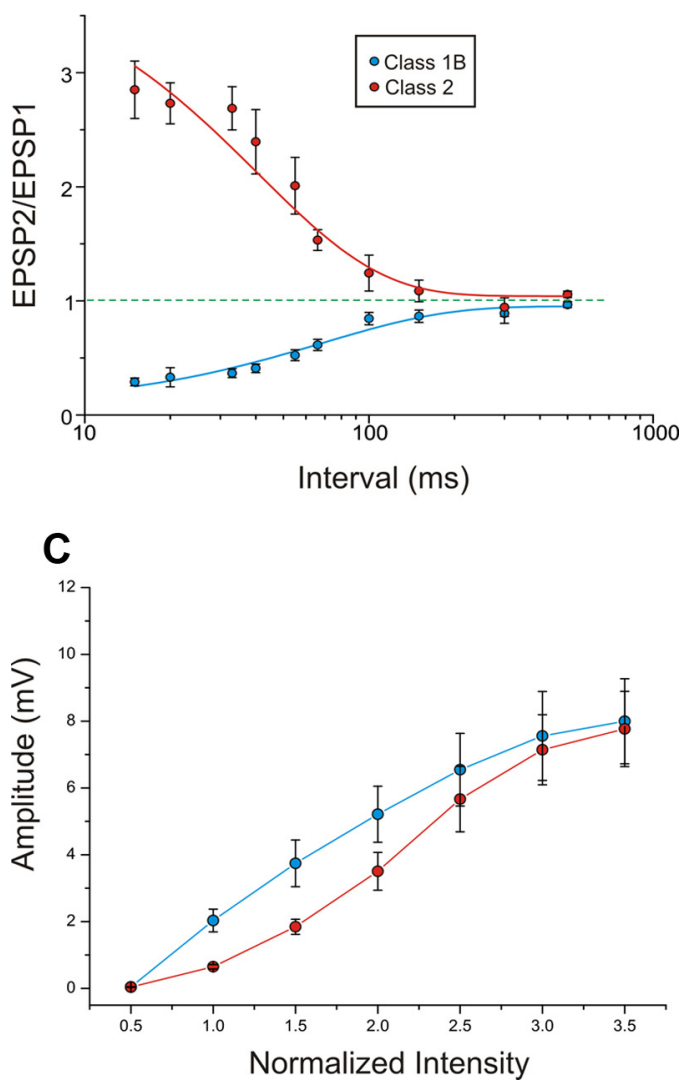

Figure 3. Properties of Class1B and Class 2 responses in the V1-to-V2 pathway. $\boldsymbol{A}$, Threedimensional graph showing the relationships among the amplitude of the first EPSP (EPSP1), the paired-pulse ratio, or amplitude of the second EPSP divided by the first (EPSP2/EPSP1), and the maximum amplitude of the $\mathrm{mGluR}$ response. $\boldsymbol{B}$, Graph showing how depression in Class 1 B responses and facilitation in Class 2 responses (mean \pm SE) increase with the decrease of the interval between the two stimuli. A first-order exponential decay is fitted to each function. $\boldsymbol{C}$, The average first EPSP amplitude is plotted against the stimulation intensity normalized to threshold value, meaning that the abscissa is divided into units that are multiples of the threshold current for each cell.

tigated its frequency dependency (Fig. 3B). Basically, for both classes, frequencies less than $\sim 10 \mathrm{~Hz}$ produce little or no pairedpulse effects, and higher frequencies produce progressively stronger effects. This pattern is in agreement with previous reports of paired-pulse effects (Thomson and West, 1993; Markram et al., 1998; Reyes et al., 1998; Thomson, 2000; Reichova and Sherman, 2004; Reig et al., 2006; Frick et al., 2007; Covic and Sherman, 2011; Viaene et al., 2011b). Based on this pattern, we chose a 15 
$\mathrm{Hz}$ as our standard stimulation frequency to test for paired-pulse effects.

Another parameter we quantified is the relationship between stimulus intensity and the size of the EPSP (Fig. 3C). The growth of the evoked EPSP with stimulus intensity is generally regarded as resulting from the recruitment of additional afferents with greater stimulation current. Whereas both classes showed a graded activation pattern, the relationship is steeper for Class $1 \mathrm{~B}$ than for Class $2(p<0.01$, two-way ANOVA). This suggests more convergence among Class 2 inputs than among Class $1 \mathrm{~B}$.

\section{Laminar relationships}

The majority of $\mathrm{V} 1$ inputs emanated from layers $2 / 3$ and 4 (Fig. $4 A$ ). We found no significant relationship between the input layer in V1 and class of input $\left(p>0.1, \chi^{2}\right.$ test). However, a different pattern is seen in the laminar relationship of recorded cells in V2 (Fig. 4B): whereas layers 2/3 and 4 had cells receiving both classes of input, layers $5 \mathrm{a}$ and 6 had cells receiving nearly exclusively Class 2 inputs, and layer $5 \mathrm{~b}$ had cells receiving nearly exclusively Class 1 inputs $\left(p<0.001, \chi^{2}\right.$ test).

To further illustrate the laminar relationships of input from V1 and recorded cells in V2, we constructed matrices from the combined data of Figure $4, A$ and $B$, and these are shown in Figure 4, $C$ and $D$. These matrices show a significant laminar relationship for both classes of input $(p<$ 0.05 for Class 1 and $p<0.001$ for Class 2 , Kruskal-Wallis test). Several patterns stand out. For Class $1 \mathrm{~B}$ inputs, those from layers $2 / 3$ of $\mathrm{V} 1$ chiefly target layers $2 / 3$ and 4 of V2, whereas inputs from layer 4 of V1 chiefly target layers 4 and 5b in V2. Layer $5 \mathrm{~b}$ of $\mathrm{V} 2$ receives input from all layers of V1. For Class 2 inputs, those innervating layer 6 come only from layers $5 b$ and 6 , and those innervating layer $5 \mathrm{a}$ come from all layers except $2 / 3$. The most prominent Class 2 pathway is from layers $2 / 3$ of $\mathrm{V} 1$ to layers $2 / 3$ of $\mathrm{V} 2$.

\section{Activation of $m G l u R s$}

In the V1-to-V2 pathway, all Class 2 responses showed activation of mGluRs, but various types of mGluR were involved, including mGluR1s, mGluR5s, and mGluR2/3s. Activation of both mGluR1s and mGluR5s produced prolonged membrane depolarization (Fig. $2 H$ ), whereas mGluR2/3 activation produced prolonged membrane hyperpolarization (Fig. $2 L$ ). The most common mGluR response observed involved the concurrent activation of mGluR1s and mGluR5s (Fig. 5A; $p<0.001, \chi^{2}$ test). The distribution of the $\mathrm{mGluR}$ responses showed a significant laminar relationship regarding the location of the recorded cells (Fig. $5 B$; $p<0.001, \chi^{2}$ test). Concomitant activation of mGluR1s and mGluR5s was seen in all layers, whereas responses showing only the activation of mGluR 1 s were exclusively observed in layers $2 / 3$,
B

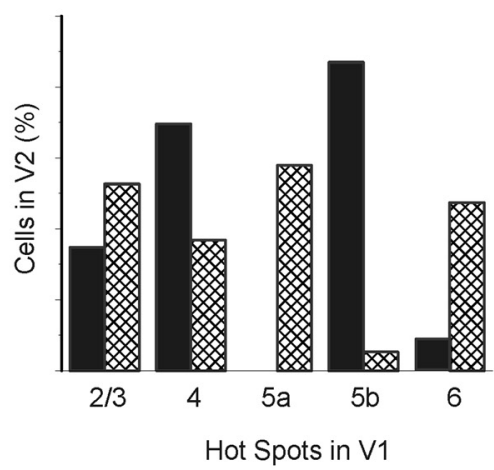

D Cells in V2

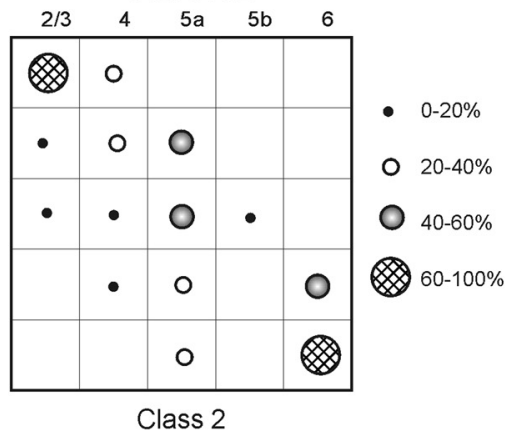

Class 1B

Class 2

Figure 4. Laminar relationships of Class1B and Class 2 responses in the V1-to-V2 pathway. A, Laminar normalized distribution of the hotspots in V1 eliciting responses in V2. B , Laminar normalized distribution of cells in V2 receiving inputs from V1. C, Matrix showing laminar relationships of Class $1 B$ responses. Each cell of the matrix shows the percentage of hotspots of the indicated layer of V1 that provides input to the indicated layer of V2. D, Laminar relationships of Class 2 responses; conventions as in $C$.
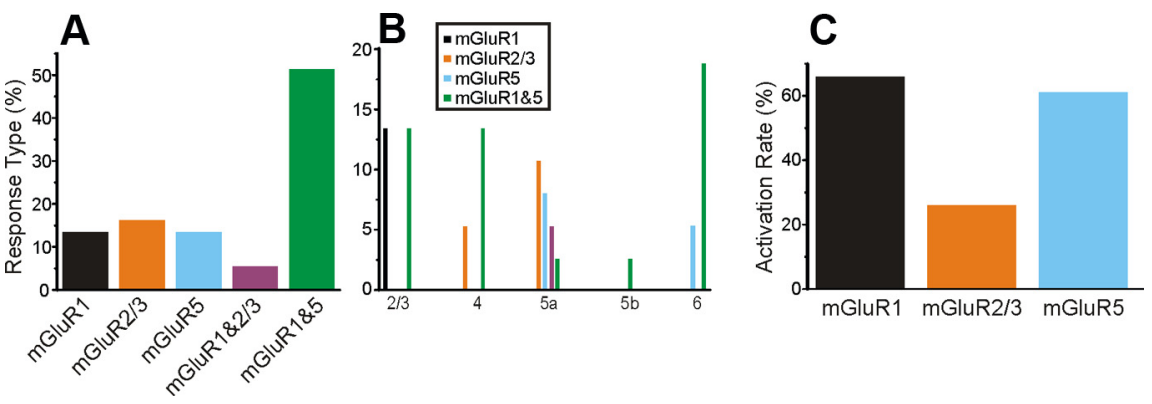

Figure 5. Activation of mGluR types in Class 2 responses in the V1-to-V2 pathway. A, Percentage of cells receiving Class 2 inputs with patterns of mGluR activation as shown. $\boldsymbol{B}$, Laminar distribution of response types by layer recorded in V2. $\boldsymbol{C}$, Activation rate of each mGluR type among cells in V2. The rate is calculated as the percentage of activation of each mGluR type regardless of the concomitant activation of other mGluR types.

and responses showing only the activation of mGluR5s were restricted to layers $5 a$ and 6 . Interestingly the mGluR2/3 responses were exclusively found in layers 4 and $5 \mathrm{a}$ (Fig. $5 B$ ). We also considered the relative occurrence of activation of each mGluR type whether singly or in combination with others. Activation of mGluR1s and mGluR5s occurred most frequently, in nearly twothirds of Class 2 responses, whereas $m$ GluR2/3 responses were evoked on only approximately one-fifth, and this distribution shows a significant difference (Fig. $5 C ; p<0.01, \chi^{2}$ test).

To determine whether the mGluRs activated in Class 2 responses were plausibly postsynaptic, a control on a group of four cells was performed. Figure $6 A-G$ provides evidence for postsynaptic activation of mGluR1s in a cell recorded in V2. The cell received Class 2 input from V1, showing paired-pulse facilitation 
A

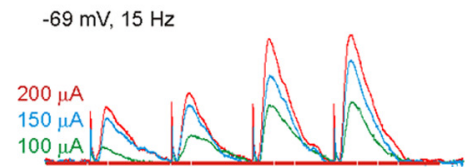

B

iGluR antagonists, $15 \mathrm{~Hz}$

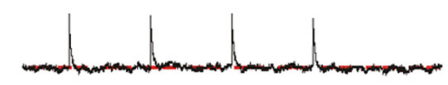

C

iGluR antagonists, $130 \mathrm{~Hz}$

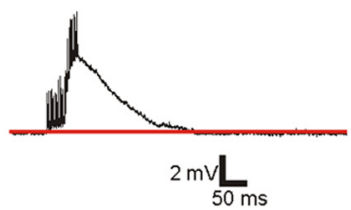

D

iGluR antagonists
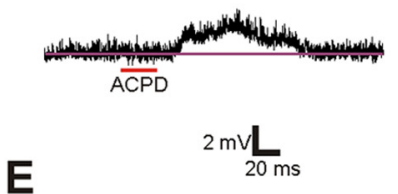

iGluR antagonists, Low $\mathrm{Ca}^{2+} / \mathrm{High} \mathrm{Mg}^{2+} \mathrm{ACSF}$

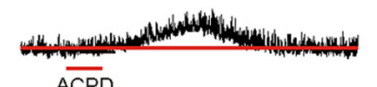

F

iGluR \& mGluR1 antagonists

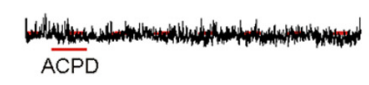

G

iGluR \& m GluR1 antagonists, $130 \mathrm{~Hz}$

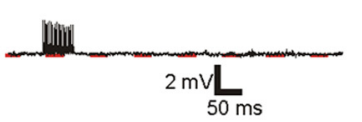

H

$-66 \mathrm{mV}, 15 \mathrm{~Hz}$

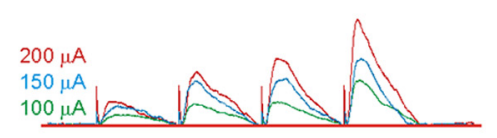

I

iGluR antagonists, $15 \mathrm{~Hz}$

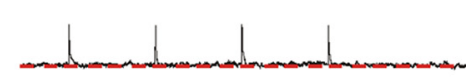

J

iGluR antagonists, $130 \mathrm{~Hz}$

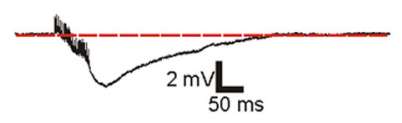

K

iGluR antagonists

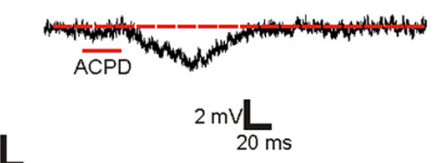

iGluR antagonists, Low $\mathrm{Ca}^{2+} / \mathrm{High} \mathrm{Mg}^{2+}$ ACSF

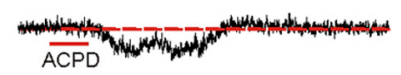

M

iGluRs \&. mGlu2/3 antagonists

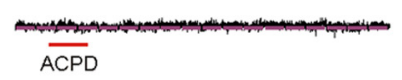

N

iGluR \& mGlu2/3 antagonists, $130 \mathrm{~Hz}$

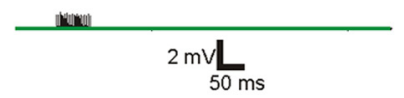

Figure 6. Postsynaptic activation of mGluRs in the V1-to-V2 pathway. A-G, Example showing a typical Class 2 response including the activation of $m G l u R 1$ for cell recorded in layer 4 of $V 2$ with hotspot in layer 4 of $V 1$. The response is graded and shows paired-pulse facilitation $(\boldsymbol{A})$, is blocked by iGluR antagonists at a stimulation rate of $15 \mathrm{~Hz}(\boldsymbol{B})$, and shows a depolarizing mGluR response after HFS with iGluR antagonists ( $($ ). With normal ACSF and iGluR antagonists, application of ACPD also evokes a consistent depolarization (D) that persists after the switch to a high $\mathrm{Mg}^{2+} / \mathrm{low}_{\mathrm{Ca}}{ }^{2+} \mathrm{ACSF}(\boldsymbol{E})$. After the subsequent addition of an mGluR1 antagonist, both ACPD $(\boldsymbol{F})$ and $\mathrm{HFS}$ after normal $\mathrm{Ca}^{2+}$ and $\mathrm{Mg}^{2+}$ were restored $(\boldsymbol{G})$ fail to evoke mGluRs. $\boldsymbol{H}-\boldsymbol{N}$, Example showing the activation of $\mathrm{mGluR2} / 3 \mathrm{~s}$; conventions as in $\boldsymbol{A}-\mathbf{G}$, with the differences that the cell is recorded in layer $5 \mathrm{a}$ of $\mathrm{V} 2$ with hotspot in layer $5 b$ of $\mathrm{V} 1$ and that $\mathrm{mGluR2} / 3$ s are evoked, leading to hyperpolarization.

(Fig. 6A), a response blocked by iGluR blockers at a low stimulation frequency (Fig. $6 \mathrm{~B}$ ), and a prolonged depolarization to HFS in the presence of iGluR blockers (Fig. 6C). Application of the general mGluR agonist ACPD in the presence of iGluR blockers also led to a slow depolarization (Fig. 6D). The normal ACSF bathing solution was then replaced with one having low $\mathrm{Ca}^{2+} /$ high $\mathrm{Mg}^{2+}$ concentrations to eliminate synaptic transmission. ACPD was applied again, and it again elicited a slow depolarizing response, meaning that this action must now be postsynaptic (Fig. 6E). This last response was blocked by the additional application of a specific mGluR1 antagonist (Fig. $6 F$ ). Figure $6 H-N$ provides similar evidence for postsynaptic activation of mGluRs going through the same steps, with the difference being that mGluR2/3s were involved in this example.

\section{Control for specificity of stimulation}

A recent study suggests that electrical stimulation in cortex could activate cells and especially axons of passage over a large distance, degrading the specificity of actual connectivity (Histed et al., 2009). However, these authors used monopolar stimulation (because they wanted specifically to analyze this methodology widely used in other experiments), which is more likely to cause wider current spread than that seen with our use of bipolar stimulation, especially because ours was guided by photostimulation. Nonetheless, to ensure the specificity of our stimulation paradigm, control experiments were performed as follows on three cells activated in the V1-to-V2 pathway. Once the footprint was identified, the stimulating electrode was moved several times to activate areas just outside the footprint. The logic here is that, if electrical stimulation of the footprint area activated axons of passage that innervated the recorded cell, then nearby locations outside the footprint should do so as well. Figure 7 shows that clear EPSPs could be evoked only by stimulation within the footprint. This does not mean that axons of passage were not activated, but, given the high degree of topography expected for these corticocortical connections, effective connectivity was seen only from the footprint region, and any axons of passage activated were unlikely to contribute significantly to the evoked responses seen.

\section{The V2-to-V1 pathway}

The analysis presented for the V2-to-V1 pathway is analogous to that presented for the V1-to-V2 pathway, and Figures 8-12 follow the pattern and conventions used for Figures 2-7.
Glutamatergic response classes

The same two classes of input as in the V1-to-V2 pathway, Classes $1 \mathrm{~B}$ and 2, and only these two, were found in the V2-to-V1 pathway. Also, the relative numbers of cells responding with each class are approximately comparable in the two pathways. In the V2- 


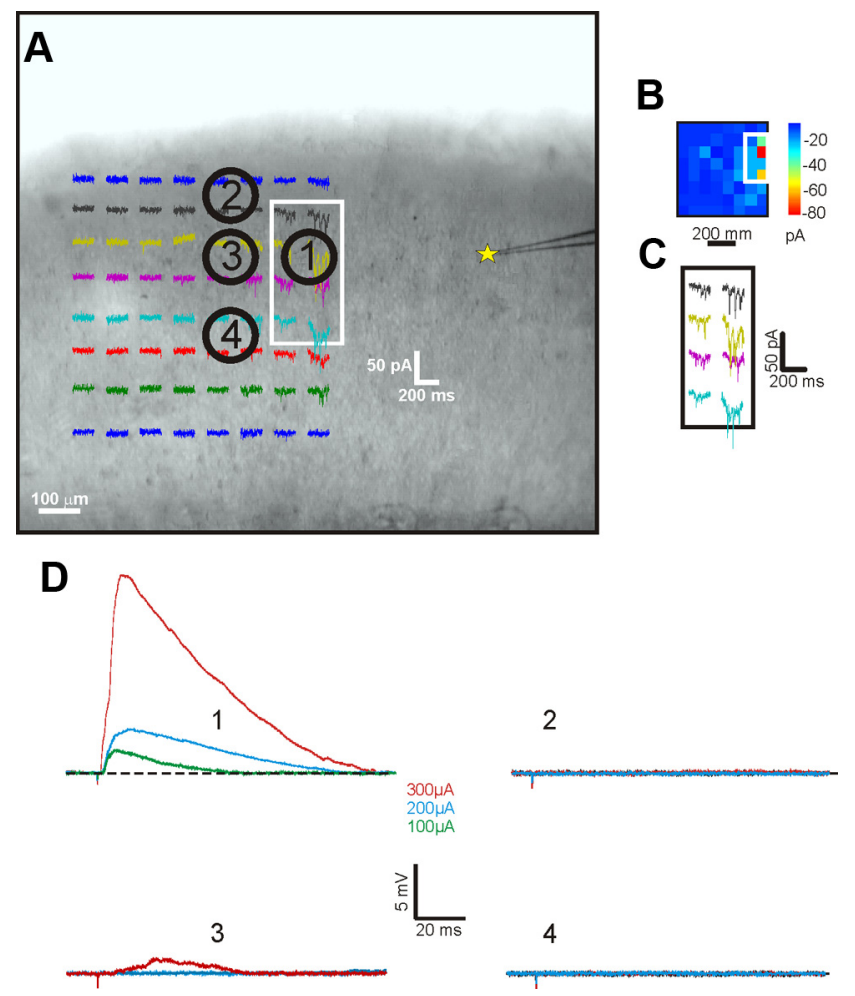

Figure 7. Control experiment in the V1-to-V2 pathway. $A$, Example of a control experiment showing a recorded cell in layer 4 of $\mathrm{V} 2$ (yellow star) and different attempts of stimulation with bipolar concentric electrode in V1 inside (1) and just outside (2-4) the footprint in layer 4. The footprint region shown in $\boldsymbol{A}$ is shown in false color in $\boldsymbol{B}$ and enlarged in $\boldsymbol{C}$. $\boldsymbol{D}$, Stimulation elicits a clear EPSP with low intensity of stimulation only when applied in the location 1 within the footprint. Stimulation at locations 2 and 4 next to the footprint evoked no detectable response, and that at location 3 evoked a small response not resembling a monosynaptic EPSP and does so only with high $(300 \mu \mathrm{A})$ stimulation intensity.

to-V1 projection, we evoked 23 Class $1 \mathrm{~B}$ responses and 37 Class 2 responses. Figure $8 A-D$ shows a Class $1 \mathrm{~B}$ response for a cell recorded in layer $5 \mathrm{~B}$ of $\mathrm{V} 1$ and activated from layer $5 \mathrm{~b}$ of $\mathrm{V} 2$. Figure $8 E-H$ shows a Class 2 response for a cell recorded in layer $5 \mathrm{a}$ of $\mathrm{V} 1$ and activated from layer $5 \mathrm{a}$ of V2; for this cell, both mGluR1s and mGluR5s were activated (Fig. $8 H$ ). Figure $8 I-L$ shows another Class 2 response for a cell recorded in layer 4 of $\mathrm{V} 1$ and activated from layer 4 of $\mathrm{V} 2$; for this cell, mGluR2/3s were activated (Fig. $8 \mathrm{~L}$ ).

As for the V1-to-V2 pathway, both response classes showed a graded response pattern (Fig. $2 B, F, J$ and Fig. $8 A, F, J$ ).

\section{Population data}

In the population data concerning the V2-to-V1 pathway, the clustering of parameters for the two classes on a threedimensional scatter plot (Fig. $9 A$ ) and the time course of the paired-pulse effects (Fig. 9B) are very similar to those found in the V1-to-V2 pathway (Fig. $3 A, B$ ). The paired-pulse ratio was lower for Class $1 \mathrm{~B}$ inputs $(0.598 \pm 0.037$ vs $2.037 \pm 0.119, p<$ $0.0001, t$ test), the amplitude of the first EPSP evoked at minimal stimulation intensity was greater for Class $1 \mathrm{~B}$ inputs $(1.590 \pm$ 0.166 vs $0.583 \pm 0.056, p<0.0001, t$ test), and the amplitude of the mGluR response was greater for Class 2 inputs (3.704 \pm 0.404 vs $0.233 \pm 0.028, p<0.0001, t$ test $)$. Finally, both classes showed a graded activation pattern, but that for Class $1 \mathrm{~B}$ inputs was steeper (Fig. 9C; $p<0.01$, two-way ANOVA).

Paired-pulse effects are strictly dependent on frequency of stimulation. The facilitation and depression effects strongly in- crease with the decrease of the interval between the paired stimuli (Fig. 9B). As in the V1-to-V2 pathway, the Class $1 \mathrm{~B}$ responses in $\mathrm{V} 1$ showed a faster rising relationship between stimulus intensity and EPSP amplitude than did the Class 2 responses (Fig. 9C) $(p<$ 0.01, two-way ANOVA).

\section{Laminar relationships}

As already seen in the V1-to-V2 pathway, all layers of V2 furnished inputs eliciting both classes of postsynaptic response in $\mathrm{V} 1$ (Fig. 10A). The hotspots of V2 are significantly related to the class of response elicited in V1 $\left(p<0.01, \chi^{2}\right.$ test $)$. Approximately half of Class $1 \mathrm{~B}$ inputs originated from layer $5 \mathrm{~b}$, whereas Class 2 responses were commonly elicited by inputs coming from all layers of V2. As in the V1-to-V2 pathway, the laminar distribution of the response classes in $\mathrm{V} 1$ is statistically related to the input class $\left(p<0.01, \chi^{2}\right.$ test) (Fig. $\left.10 \mathrm{~B}\right)$. Layers $2 / 3$ and 4 have cells with both classes of input, whereas layer $5 \mathrm{~b}$ has cells predominantly with Class $1 \mathrm{~B}$ input, and layers $5 \mathrm{a}$ and 6 with Class 2 input.

Connectivity matrices were constructed in a manner analogous to those for Figure 4, $C$ and $D$ (Fig. 10C,D). These matrices show a significant laminar relationship only for Class 2 inputs $(p<0.001$, Kruskal-Wallis test). For Class $1 \mathrm{~B}$ responses, inputs mostly emanated from layers $2 / 3$ and $5 b$ of $V 2$, those from layers $5 \mathrm{~b}$ principally targeted layers $2 / 3$ and $5 \mathrm{~b}$ of $\mathrm{V} 1$, whereas those coming from layer $2 / 3$ chiefly targeted layers 4 and 5 b. For Class 2 inputs, the most prominent pathway is from layer 6 of $\mathrm{V} 2$ to layer 6 of V1. There are other patterns that emerged. Inputs coming from layer $2 / 3$ of V2 chiefly target layer $2 / 3$ and 4 of V1. Inputs originating from layers $5 \mathrm{~b}$ of $\mathrm{V} 2$ had their targets in subgranular layer of V1. Finally, the principal destination of inputs coming from layers 4 and $5 \mathrm{a}$ of $\mathrm{V} 2$ are cells located, respectively, in layers 4 and $5 \mathrm{a}$ of $\mathrm{V} 1$.

\section{Activation of $m$ GluRs}

All cells recorded in V1 showing Class 2 inputs from V2 demonstrated a clear mGluR response, and the distribution of the various mGluRs involved are shown in Figure 11 in a manner similar to that shown in Figure 5 for the V1-to-V2 pathway. The most common mGluR pattern evoked involved both mGluR1s and mGluR5s (Fig. 11A; $p<0.001, \chi^{2}$ test), whereas mGluR2/3s were evoked relatively rarely $\left(p<0.001, \chi^{2}\right.$ test $)$. Unlike the case in the V1-to-V2 pathway, no significant laminar relationship was found concerning the distribution of different mGluR response types (Fig. $11 B ; p>0.1, \chi^{2}$ test). The relative rates of activation of the various $\mathrm{mGluR}$ types also show a predominance of mGluR1s and mGluR5s with rare mGluR2/3s (Fig. 11C; $p<0.001, \chi^{2}$ test).

\section{Control for specificity of stimulation}

The specificity of stimulation in V2 on three cells was assessed by performing the same control experiment described in the V1to-V2 pathway as shown in Figure 7. Consistent EPSPs were evoked only by stimulation of the footprint and not by stimulation of locations just outside the footprint (Fig. 12).

\section{Comparison between V1-to-V2 and V2-to-V1 pathways}

A comparison between the V1-to-V2 and V2-to-V1 pathways shows remarkably similar laminar relationships for the location of afferents and target cells, with the only difference related to layer 4 (Fig. 13 A, B). That is, the V1 to V2 pathway shows approximately equal numbers of Class $1 \mathrm{~B}$ and 2 inputs emanating from layer 4 , but in the reverse pathway, layer 4 produced mainly Class 2 afferents, and even this difference barely reached statistical significance ( $p<0.05$, Fisher's exact test). Given the large number of comparisons yielding just one barely significant difference, we 


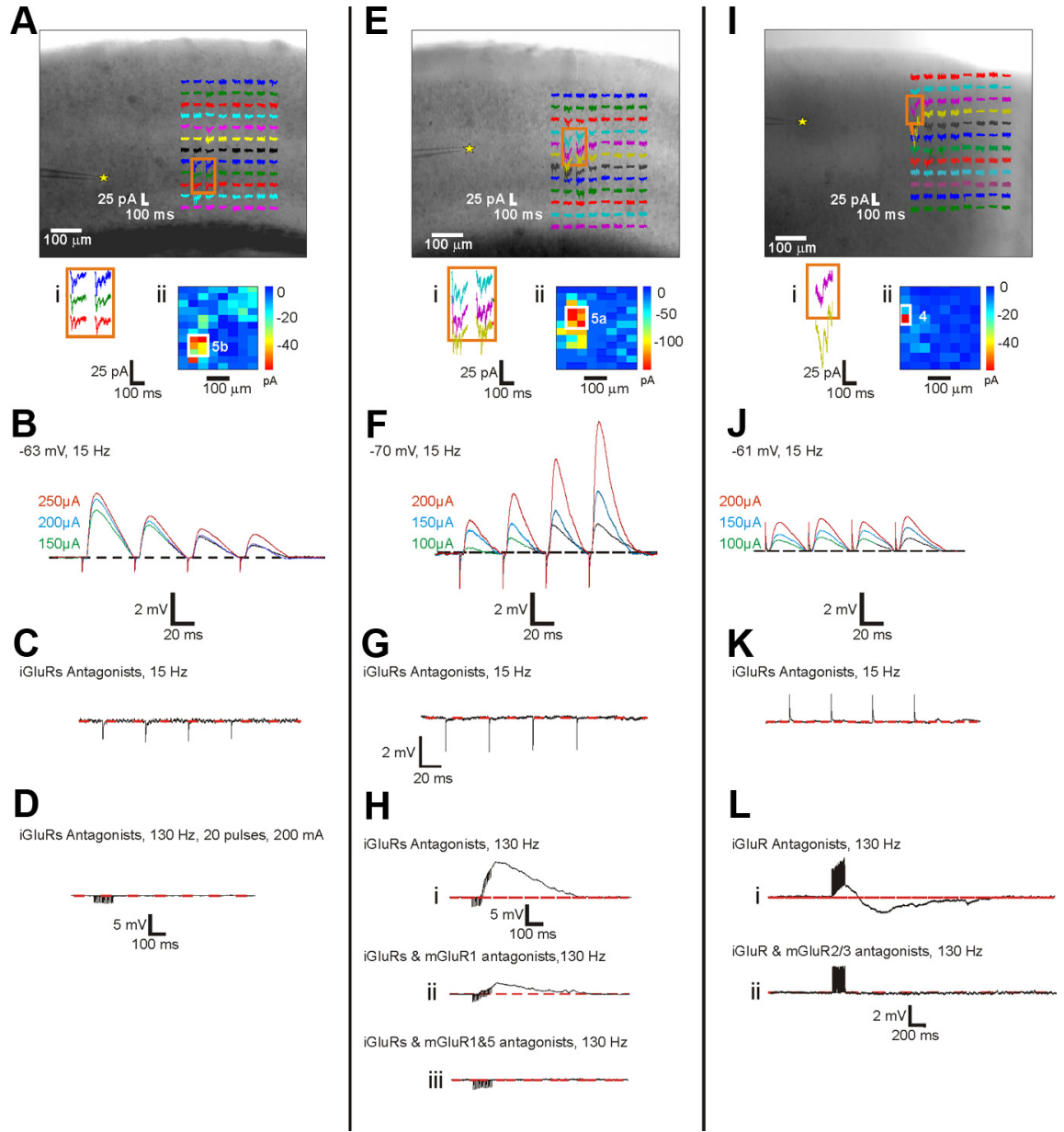

Figure 8. Response examples in the V2-to-V1 pathway. Conventions as in Figure 2. $A-D$, Example of a Class 1B response with cell in layer $5 b$ of $\mathrm{V} 1$ and footprint in layer $5 b$ of V2. $\boldsymbol{E}-\boldsymbol{H}$, Example of a Class 2 response with cell in layer $5 \mathrm{a}$ of $\mathrm{V} 2$ and footprint in layer 5 a of V1, and in this case both mGluR1s and mGluR5s were evoked. $I-L$, Example of a Class 2 response recorded in cell in layer 4 of $\mathrm{V} 2$ and elicited by a footprint found in layer 4 of $\mathrm{V} 1$, and in this case $\mathrm{mGluR2} / 3 \mathrm{~s}$ were evoked. We cannot account for the initial depolarization in $\boldsymbol{L}$.

conclude that our data do not support significant laminar differences for the two directions of the V1-to-V2 pathway with regard to the properties we evaluated. Likewise, a statistical comparison of the matrices shown in Figures 4, $C$ and $D$, and $10, C$ and $D$, show no statistically significant differences ( $p>0.1$ on all tests except one, for which $0.05<p<0.1$ on a series of Kruskal-Wallis tests). Furthermore, Figure $13 \mathrm{C}$ shows that the profile of mGluRs activated was similar in the two pathways for mGluR1s and mGluR5s. However, the pattern for $\mathrm{mGluR2} / 3 \mathrm{~s}$ was different because these were activated on cells in layer $5 \mathrm{a}$ only in the V1-to-V2 pathway, but this difference also barely reached statistical significance $(p<$ $0.05, \chi^{2}$ test).

\section{Notes on both pathways}

For laser uncaging experiments, the distance from the recorded cell to the hotspot ranged from 250 to $470 \mu \mathrm{m}$ in both pathways (V1-to-V2, $343.59 \pm 5.98 \mu \mathrm{m}$; V1-to-V2, $342.90 \pm 9.17 \mu \mathrm{m}$ ). The mean distances did not differ significantly between the two pathways ( $p>0.1, t$ test). Neither the prevalence of Class $1 \mathrm{~B}$ versus Class 2 responses nor the specific parameters of pairedpulse ratio, initial EPSP amplitude, or extent of the mGluR response depended on that distance $(p>0.1$ on all correlation coefficients). Furthermore, synaptic connections are known to change during development in mice, and we studied animals ranging in age from 10 to $19 \mathrm{~d}$ postnatal. We found no correlation with the age of the animal and the prevalence of Class $1 \mathrm{~B}$ or Class 2 response types or with any of the parameters noted above $(p>0.1$ on all correlation coefficients).

\section{Comparison between auditory and visual systems}

The experiments reported here should be seen as analogous to those reported previously from this laboratory using the same techniques to analyze the connections in both directions between the first (A1) and second $(\mathrm{A} 2 \mathrm{v})$ auditory areas in mouse cortex (Covic and Sherman, 2011). A close comparison of results is thus useful in determining any possible patterns that may be generalized for these sorts of corticocortical connections. Of great significance is the fact that, in both studies, the same two classes of responses, Classes $1 \mathrm{~B}$ and 2, and only these two, were found. The number of responses per class is also quite similar. In the V1-to-V2 pathway, the number of Class 2 responses is higher in both systems: 36 versus 23 for V1-to-V2 and 55 versus 36 for A1-to-A2v. In the other direction, the number of Class 2 responses is still higher in the visual system (36 vs 23), whereas in the auditory system, the responses are 36 for each class. Nevertheless, this difference is not significant $(p>0.1$, Fisher's exact test).

\section{Pattern of Class $1 B$ and 2 afferents}

The profile of laminar distributions of these classes, for both afferent source and target cell locations, shows similar relationships when comparing the two systems (Fig. 14). Only two barely significant differences ( $p<0.05$, Fisher's exact test) are seen among all comparisons, and these are in the V2-to-V1 pathway (Fig. 14C,D). As above for the comparison of the two directions between V1 and V2, we conclude from these comparisons that there is a remarkable similarity in the laminar patterns of the connections in the auditory and visual systems in both directions.

Pattern of mGluR types evoked from Class 2 inputs Qualitatively, the pattern of mGluR types evoked from Class 2 inputs was similar in the two systems. In every Class 2 afferentevoked mGluRs, the same types were seen (mGluR1, mGluR5, and mGluR2/3), and mGluR2/3s were the least common to be evoked. The one quantitative difference seen was relatively more mGluR5s in the visual pathways, in both directions, when compared with the auditory pathways (Fig. 15; $p<0.01, \chi^{2}$ test for both comparisons).

\section{Discussion}

The present study characterized glutamatergic excitatory corticocortical connections between V1 and V2 in both directions. All synaptic responses can be clearly divided in two classes. Class $1 \mathrm{~B}$ has large initial EPSPs with paired-pulse depression and activates only iGluRs; Class 2 has small initial EPSPs with paired-pulse 

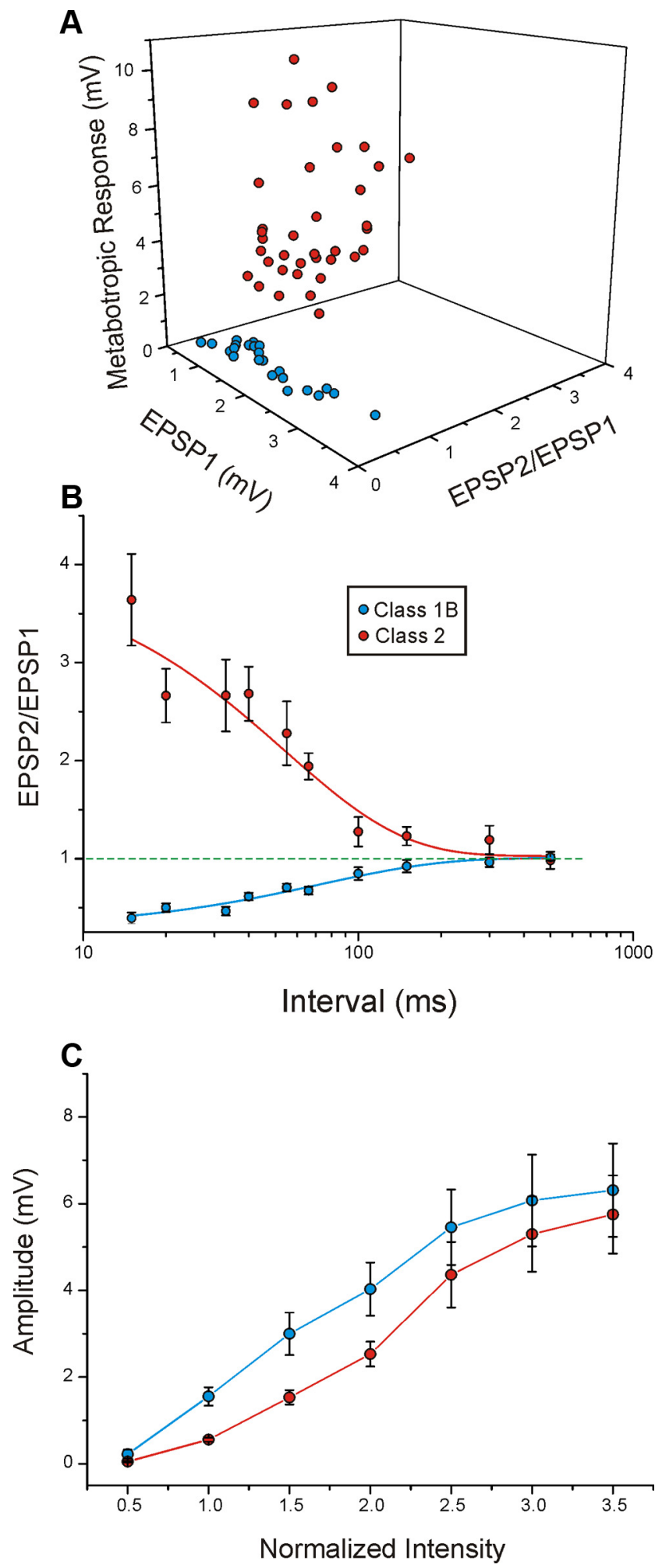

Figure 9. Properties of Class1B and Class 2 responses in the V2-to-V1 pathway. Conventions as in Figure 3.

facilitation and activates both iGluRs and mGluRs. The fact that these projections are functionally heterogeneous suggests that anatomical pathway tracing alone cannot determine the importance of a projection: understanding the different classes involved and their different functional features must be part of the equation. Of additional interest is the observation that, although most
mGluRs activated by Class 2 inputs are Group I (mGluR1 and mGluR5) and thus depolarizing, some are Group II (mGluR2/3) and thus hyperpolarizing. Finally, the laminar pattern in both directions (V1-to-V2 and V2-to-V1) are correlated to input class and are surprisingly similar. However, because our data come from brain slices, we emphasize that we cannot be certain of possible connections that were cut in our preparation and how this might affect data interpretation.

We have previously described different glutamatergic inputs involving cortical circuits and have adopted the following terminology (Covic and Sherman, 2011). Class 1A inputs have all the properties of Class $1 \mathrm{~B}$ inputs except that the former are activated in an all-or-none manner, whereas that latter are activated in a graded manner. We conclude that this relatively minor difference dictates terminology suggesting closer affinity between Classes $1 \mathrm{~A}$ and $1 \mathrm{~B}$ than either with Class 2 , but it seems unlikely that this is the last word for either this classification or this terminology.

In our previous study of the auditory cortices (Covic and Sherman, 2011), we have discussed the possible functional significance of Class $1 \mathrm{~B}$ and 2 inputs and do not repeat that here.

\section{Interpretation of electrical stimulation data}

Much of our data derive from electrical stimulation, and we place bipolar stimulating electrodes on hotspots determined by photostimulation, which identifies a known connection and the source of the afferent cell bodies and proximal dendrites. However, we cannot completely rule out the possibility that, in addition to cell bodies and dendrites, we are stimulating axons, either of passage or antidromically, leading to additional possible sources of input to connected cells. For the following reasons, we do not believe that this potential pitfall requires us to significantly alter our conclusions. First, the connectivity between areas is highly topographical (Schuett et al., 2002; Wang and Burkhalter, 2007), and so if axons passing through the stimulation site from distant locations were stimulated, they would not likely innervate the patched cell in the other visual area; this indeed is supported by our control experiments shown in Figures 7 and 12. What we cannot so easily rule out is the possibility that cells in the topographically matched region of the target area project to the region of our stimulating electrodes, are activated, and a local collateral innervates our recorded cell. However, this would be a problem in the specific logic of our experiments only if this "antidromic" connection were different from the "orthodromic" ones we activate by stimulating the hotspot. If they were different, we would obtain a mixed response, which we are able to identify (Covic and Sherman, 2011;Viaene et al., 2011b), and such responses were not seen in the present study. Thus, if any antidromic responses did manage to contaminate our recordings, they did not affect the classification of inputs, which is the main point of this study.

\section{Comparison of the V1-to-V2 and V2-to-V1 pathways}

The distribution of Class $1 \mathrm{~B}$ and 2 inputs in the connections between V1 and V2 has a laminar dependence that is similar in both directions (Figs. 4, 10, 13). Our initial expectation was that the feedforward pathway, presumably V1-to-V2, should be more dominated by information bearing inputs, and the feedback pathway, presumably V2-to-V1, by modulatory inputs; we thus expected that the V1-to-V2 pathway would be more dominated by Class $1 \mathrm{~B}$ inputs, but this was not the case. A similar relationship was found for the auditory cortex (Covic and Sherman, 2011). The main surprise is the strong representation of Class $1 \mathrm{~B}$ inputs in the presumed feedback pathway, and it will be of particular interest to determine the function of this projection. 
A

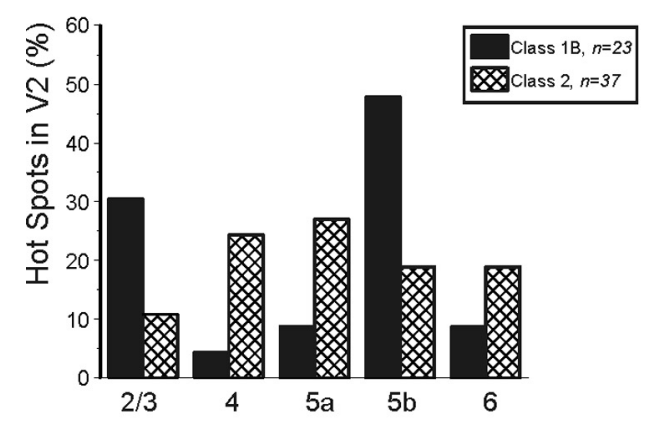

B

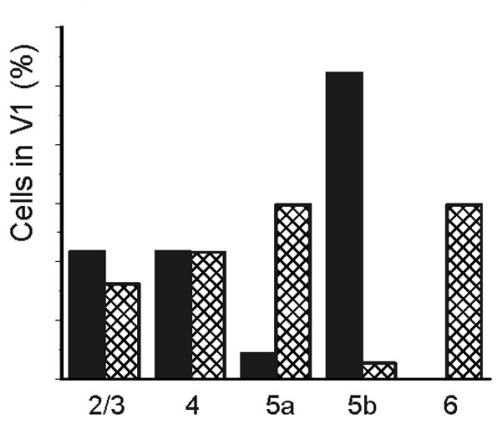

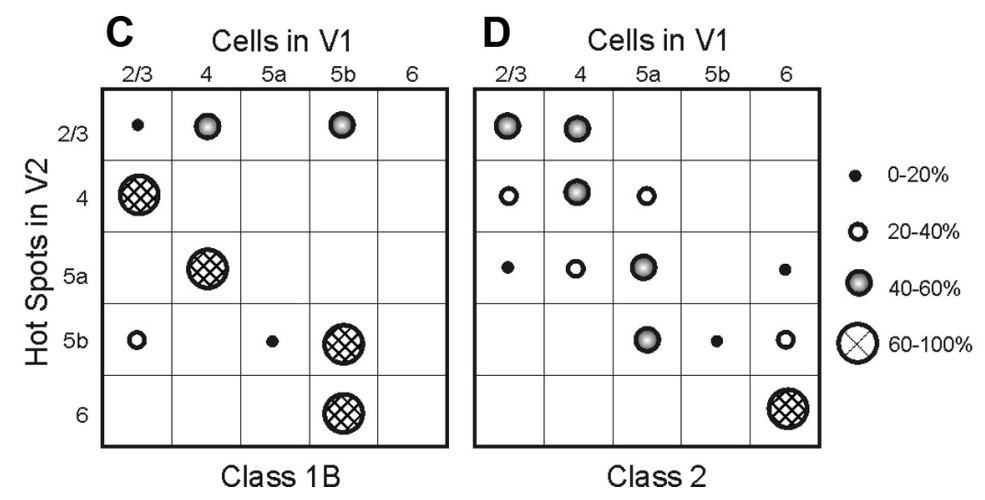

Figure 10. Laminar relationships of Class $1 B$ and Class 2 responses in the V2-to-V1 pathway. Conventions as in Figure 4.
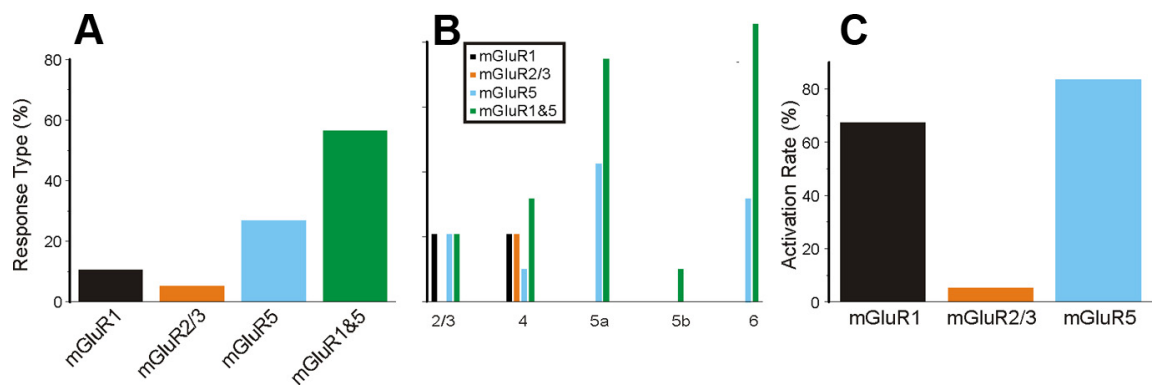

Figure 11. Postsynaptic activation of mGluRs in the V2-to-V1 pathway. Conventions as in Figure 5.

layer. This specificity is consistent with immunohistological results, indicating a concentration of mGluR2/3 labeling in layer 4 (Reid and Romano, 2001; Lee and Sherman, 2009). Postsynaptic activation of mGluR2/3s in layer 4 cells is also evoked from layer 6 of the same area (Lee and Sherman, 2009). It thus appears that layer 4 cells postsynaptic to thalamic input can be inhibited by activation of mGluR2/3s from multiple afferent sources.

\section{Comparison with other studies}

There is a general problem comparing laminar relationships seen in most anatomical studies of corticocortical projections with ours. That is, the anatomical studies generally specify the specific layer in which a projection terminates, whereas our study specifies the specific layer in which the postsynaptic cell body resides. For instance, a pyramidal cell in layer 5 may receive an afferent input onto its apical dendrite in layers $2 / 3$ that can produce an EPSP: the anatomy would determine the projection to layers $2 / 3$, and our approach would place the target in layer 5 . Both kinds of data are relevant, but the obvious discrepancy in the interpretation of the data must be understood.

With this caveat, it is difficult to see how most data of corticocortical connections, which are anatomical (see Introduction), relate to ours. For visual cortical areas of the rhesus monkey, Felleman and Van Essen (1991) have produced arguably the most influential account of corticocortical connectivity, identifying laminar differences between presumed feedforward, feedback, and lateral projections. None of these patterns match the ones we have seen here. In addition to the prob-

\section{Laminar relationships}

In both directions, inputs to layers $2-4$ are mixed but layer $5 \mathrm{~b}$ receives predominantly Class $1 \mathrm{~B}$ inputs, whereas layers $5 \mathrm{a}$ and 6 receive predominantly Class 2 inputs. Layer $5 \mathrm{~b}$ represents the locus of corticofugal projections to many subcortical sites, typically via branching axons (Bourassa and Deschênes, 1995; Bourassa et al., 1995; Deschênes et al., 1998; Veinante et al., 2000), and these targets include higher-order thalamic nuclei (Guillery, 1995; Sherman and Guillery, 2006). This suggests that each area can strongly drive the corticofugal projections of the other area. Layer 6 represents the locus of the other main corticofugal output, namely, a feedback projection to the thalamus (Sherman and Guillery, 2006). The laminar pattern thus also suggests that each area can influence through modulation the control of the other area's own thalamic input. Finally, it appears that each area can influence the other with both classes of input at the main site of thalamocortical input in layer 4.

We also found laminar specificity for mGluR2/3 activation among Class 2 inputs. In both directions, mGluR2/3 activation was seen in layer 4 , and in addition, this was seen in layer $5 \mathrm{a}$ in the V1-to-V2 pathway. Such activation was not seen in any other lems noted in the preceding paragraph, this is possibly also attributable to species differences, and it remains an issue to be resolved.

We note some discrepancies with certain observations in rodents not explained by the above discussion. Simmons et al. (1982) used retrograde labeling in the mouse and concluded that layer 4 of V2 does not produce corticocortical connections in V1, and yet we see many footprints for such projections in layer 4 (Fig. 10A). One possible explanation for this discrepancy is that these authors note that, in the experiment most relevant to our study, "The injection site itself was restricted to the upper layers...," and thus may have missed connections to lower layers.

\section{Conclusions: comparison with auditory cortices}

The data presented here are in remarkable agreement with our previous, analogous study of connections between the auditory cortical areas A1 and A2v (Covic and Sherman, 2011). Not only could all projections in both studies be attributed to Classes $1 \mathrm{~B}$ and 2, but also the laminar relations of these inputs have a similar profile. There are few differences concerning some details that are described in Results, but these seem minor compared with the 

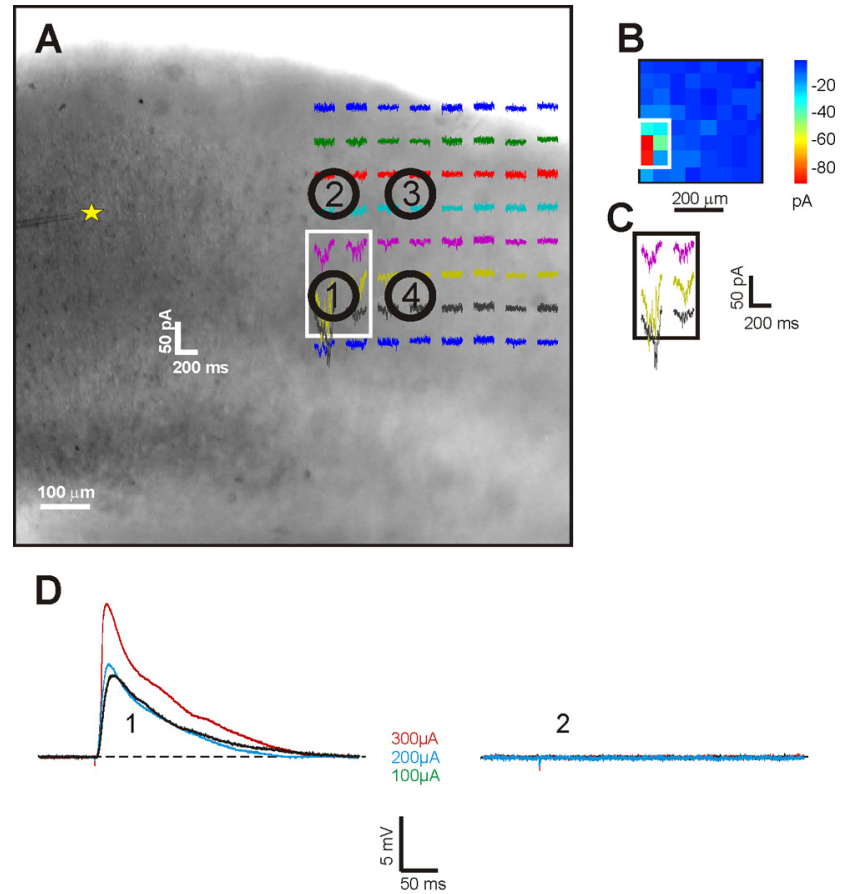

3

4

Figure 12. Control experiment in the V2-to-V1 pathway. Example of a control experiment showing a recorded cell in layer 4 of $\mathrm{V} 1$ (yellow star) and different attempts of stimulation with bipolar concentric electrode in V2 inside (1) and outside (2-4) the footprint in layer 5a. A-D, Conventions as in Figure 7. As shown in $\boldsymbol{D}$, only stimulation in the footprint evoked EPSPs in the recorded cell.

remarkable overall similarity. Obviously, more examples of corticocortical connectivity are needed, including more species, but the results noted here offer encouragement that this represents the beginnings of a general plan of corticocortical connectivity, at least in the mouse.

\section{References}

Atzori M, Lei S, Evans DI, Kanold PO, Phillips-Tansey E, McIntyre O, McBain CJ (2001) Differential synaptic processing separates stationary from transient inputs to the auditory cortex. Nat Neurosci 4:1230-1237.

Beck PD, Kaas JH (1998a) Cortical connections of the dorsomedial visual area in prosimian primates. J Comp Neurol 398:162-178.

Beck PD, Kaas JH (1998b) Cortical connections of the dorsomedial visual area in New World owl monkeys (Aotus trivirgatus) and squirrel monkeys (Saimiri sciureus). J Comp Neurol 400:18-34.

Bourassa J, Deschênes M (1995) Corticothalamic projections from the primary visual cortex in rats: a single fiber study using biocytin as an anterograde tracer. Neuroscience 66:253-263.

Bourassa J, Pinault D, Deschênes M (1995) Corticothalamic projections from the cortical barrel field to the somatosensory thalamus in rats: a single-fibre study using biocytin as an anterograde tracer. Eur J Neurosci 7:19-30.

Callaway EM, Katz LC (1993) Photostimulation using caged glutamate reveals functional circuitry in living brain slices. Proc Natl Acad Sci U S A 90:7661-7665.

Canepari M, Nelson L, Papageorgiou G, Corrie JE, Ogden D (2001) Photochemical and pharmacological evaluation of 7-nitroindolinyl-and 4-methoxy-7-nitroindolinyl-amino acids as novel, fast caged neurotransmitters. J Neurosci Methods 112:29-42.

Coogan TA, Burkhalter A (1990) Conserved patterns of cortico-cortical connections define areal hierarchy in rat visual cortex. Exp Brain Res 80:49-53.

Covic EN, Sherman SM (2011) Synaptic properties of connections between the primary and secondary auditory cortices in mice. Cereb Cortex 21:2425-2441.
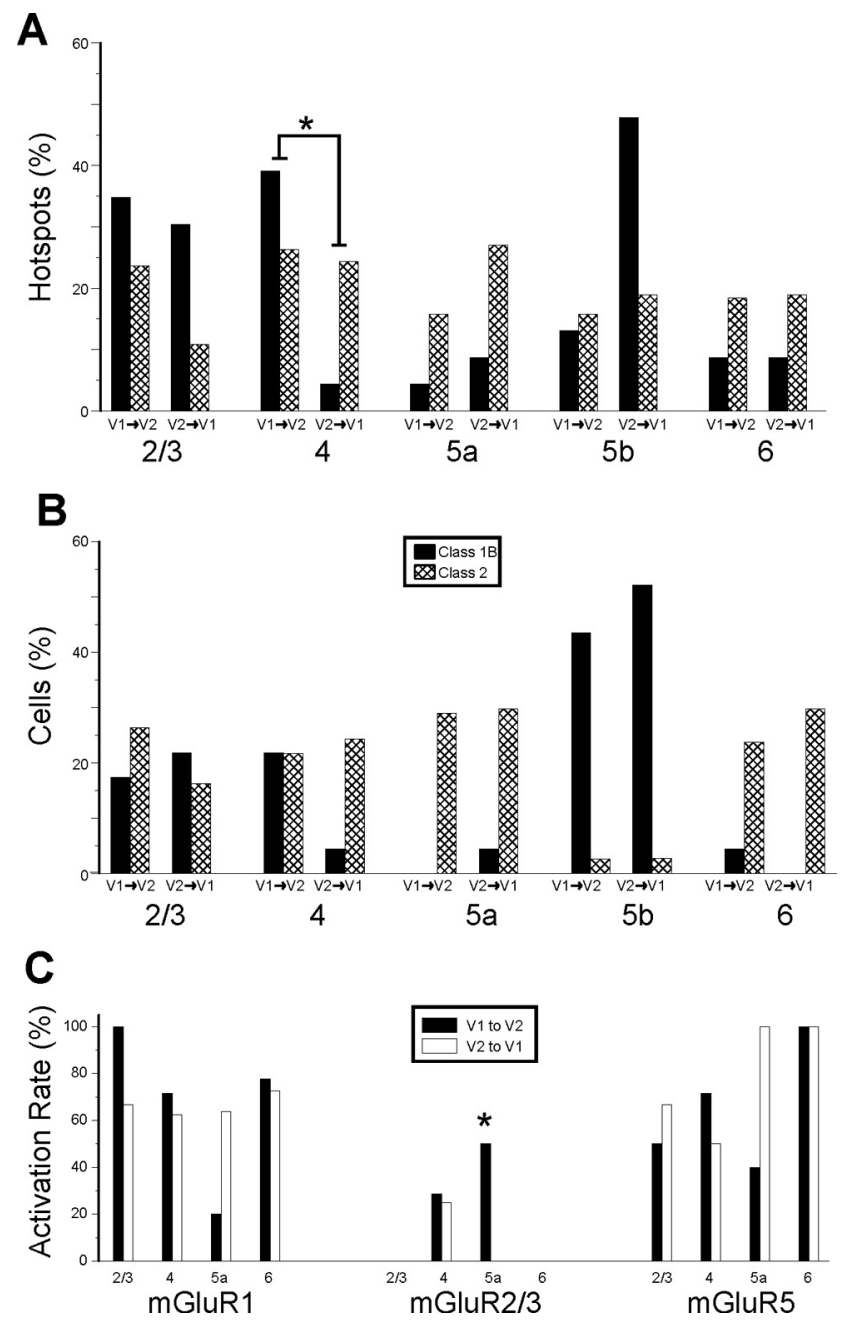

Figure 13. Comparison between V1-to-V2 and V2-to-V1 pathways. $A$, Laminar normalized distribution of the footprints showing class of efferent for the two pathways. Only the footprints originating in layer 4 show a significant difference $\left({ }^{*} p<0.05\right.$, Fisher's exact test). $\boldsymbol{B}$, Laminar normalized distribution of recorded cells showing class of input. The distribution is not significantly different for the two pathways. C, Laminar distribution of recorded cells with Class 2 inputs showing types of $m G$ luR evoked. The only difference found in the two pathways is in layer $5 a$, in which mGluR2/3 activation was found only for the V1-to-V2 pathway ( ${ }^{*} p<0.05$, a $\chi^{2}$ test).

Deschênes M, Veinante P, Zhang ZW (1998) The organization of corticothalamic projections: reciprocity versus parity. Brain Res Rev 28:286-308.

Domenici L, Harding GW, Burkhalter A (1995) Patterns of synaptic activity in forward and feedback pathways within rat visual cortex. J Neurophysiol 74:2649-2664.

Dong H, Shao Z, Nerbonne JM, Burkhalter A (2004) Differential depression of inhibitory synaptic responses in feedforward and feedback circuits between different areas of mouse visual cortex. J Comp Neurol 475:361-373.

Dudek SM, Friedlander MJ (1996) Intracellular blockade of inhibitory synaptic responses in visual cortical layer IV neurons. J Neurophysiol 75:2167-2173.

Felleman DJ, Van Essen DC (1991) Distributed hierarchical processing in the primate. Cereb Cortex 1:1-47.

Fleidervish IA, Binshtok AM, Gutnick MJ (1998) Functionally distinct NMDA receptors mediate horizontal connectivity within layer 4 of mouse barrel cortex. Neuron 21:1055-1065.

Frick A, Feldmeyer D, Sakmann B (2007) Postnatal development of synaptic transmission in local networks of L5A pyramidal neurons in rat somatosensory cortex. J Physiol 585:103-116.

Guillery RW (1995) Anatomical evidence concerning the role of the thalamus in corticocortical communication: a brief review. J Anat $187: 583-592$ 

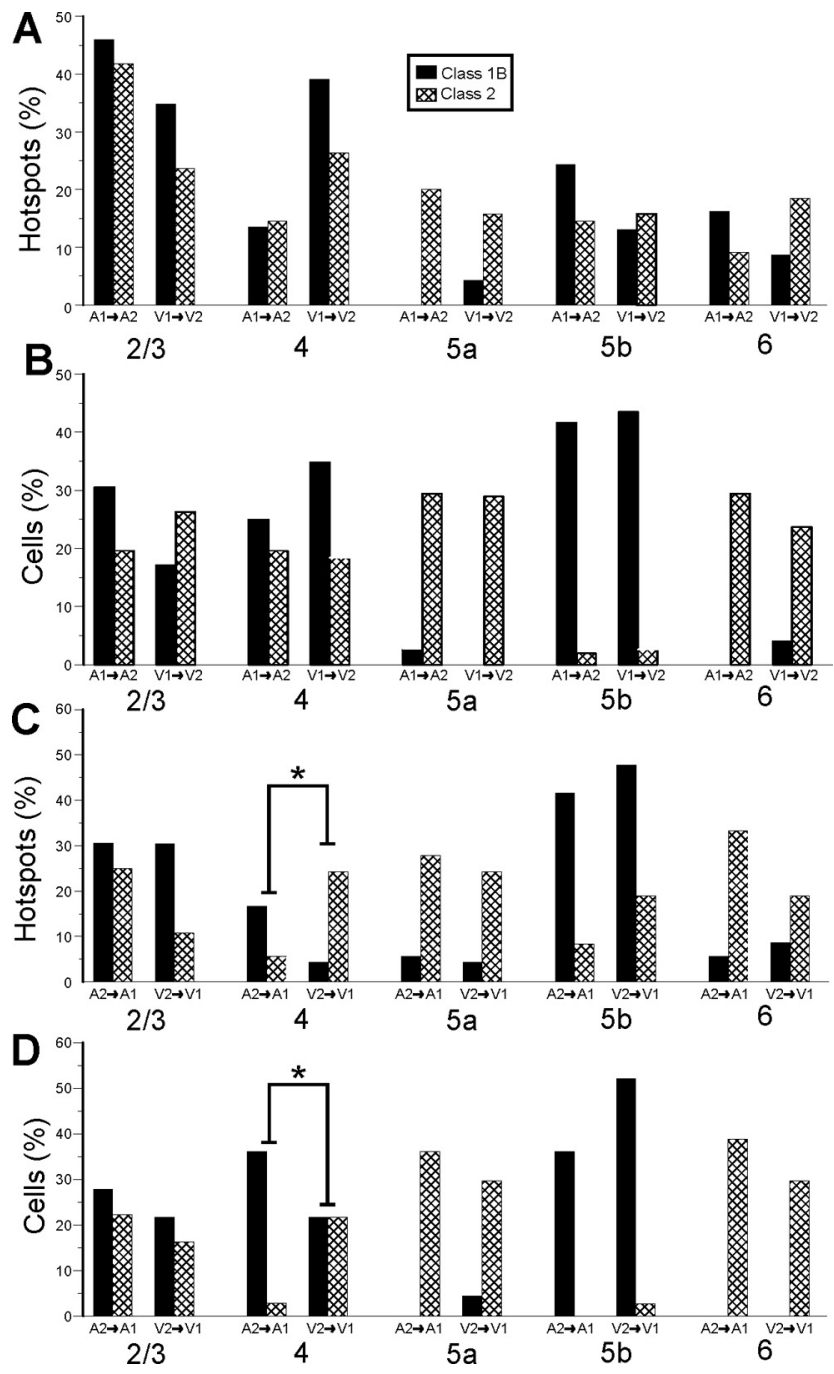

Figure 14. Comparison of laminar relationships between auditory and visual pathways. Data for the auditory pathways (A1-to-A2v and A2v-to-A1) for this figure and Figure 15 are taken from Covic and Sherman (2011). A, Comparison between A1-to-A2v and V1to-V2 pathways for laminar normalized distribution of footprints. $B$, Comparison between A1-to-A2v and V1-to-V2 pathways for laminar normalized distribution of recorded cells. C, Comparison between A2v-to-A1 and V2-to-V1 pathways for the laminar distribution of footprints. D, Comparison between A2v-to-A1 and V2-to-V1 pathways for laminar location of recorded cells. ${ }^{*} p<0.05$.
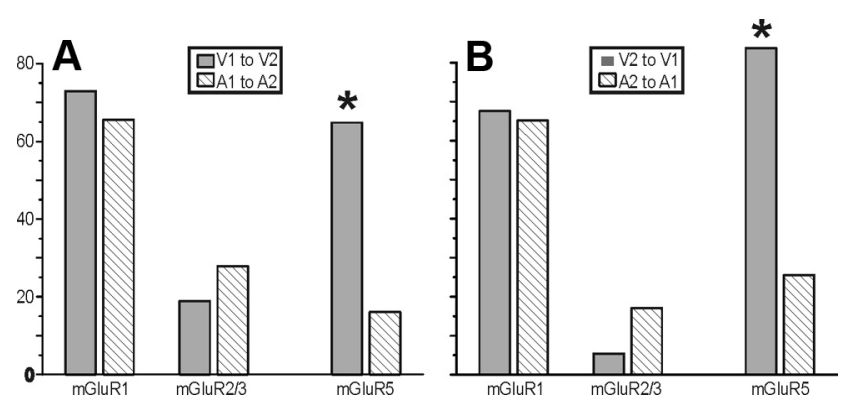

Figure 15. Comparison for Class 2 mGluR activation between auditory and visual pathways. The relative percentage is plotted for each mGluR type, and the total exceeds $100 \%$ in many cases because many cells showed multiple types (e.g., Fig. $8 \boldsymbol{H}, \mathrm{L}$ ). $\boldsymbol{A}$, Comparison for the primary to secondary direction. $\boldsymbol{B}$, Comparison for the secondary to primary direction. ${ }^{*} p<0.01$.
Hishida R, Hoshino K, Kudoh M, Norita M, Shibuki K (2003) Anisotropic functional connections between the auditory cortex and area 18a in rat cerebral slices. Neurosci Res 46:171-182.

Histed MH, Bonin V, Reid RC (2009) Direct activation of sparse, distributed populations of cortical neurons by electrical microstimulation. Neuron 63:508-522.

Kaas JH, Collins CE (2001) The organization of sensory cortex. Curr Opin Neurobiol 11:498-504.

Lam YW, Sherman SM (2005) Mapping by laser photostimulation of connections between the thalamic reticular and ventral posterior lateral nuclei in the rat. J Neurophysiol 94:2472-2483.

Lee CC, Sherman SM (2008) Synaptic properties of thalamic and intracortical inputs to layer 4 of the first- and higher-order cortical areas in the auditory and somatosensory systems. J Neurophysiol 100:317-326.

Lee CC, Sherman SM (2009) Glutamatergic inhibition in sensory neocortex. Cereb Cortex 19:2281-2289.

Lee CC, Sherman SM (2010) Topography and physiology of ascending streams in the auditory tectothalamic pathway. Proc Natl Acad Sci U S A 107:372-377.

Markram H, Wang Y, Tsodyks M (1998) Differential signaling via the same axon of neocortical pyramidal neurons. Proc Natl Acad Sci U S A 95:5323-5328.

Maunsell JH, van Essen DC (1983) The connections of the middle temporal visual area (MT) and their relationship to a cortical hierarchy in the macaque monkey. J Neurosci 3:2563-2586.

McCormick DA, von Krosigk M (1992) Corticothalamic activation modulates thalamic firing through glutamate "metabotropic" receptors. Proc Natl Acad Sci U S A 89:2774-2778.

Nowak LG, James AC, Bullier J (1997) Corticocortical connections between visual areas 17 and 18a of the rat studied in vitro: spatial and temporal organisation of functional synaptic responses. Exp Brain Res $117: 219-241$.

Petrof I, Sherman SM (2009) Synaptic properties of the mammillary and cortical afferents to the anterodorsal thalamic nucleus in the mouse. J Neurosci 29:7815-7819.

Reichova I, Sherman SM (2004) Somatosensory corticothalamic projections: distinguishing drivers from modulators. J Neurophysiol 92:2185-2197.

Reid SN, Romano C (2001) Developmental and sensory-dependent changes of group II metabotropic glutamate receptors. J Comp Neurol 429:270-276.

Reig R, Gallego R, Nowak LG, Sanchez-Vives MV (2006) Impact of cortical network activity on short-term synaptic depression. Cereb Cortex 16:688-695.

Reyes A, Lujan R, Rozov A, Burnashev N, Somogyi P, Sakmann B (1998) Target-cell-specific facilitation and depression in neocortical circuits. Nat Neurosci 1:279-285.

Rockland KS, Pandya DN (1979) Laminar origins and terminations of cortical connections of the occipital lobe in the rhesus monkey. Brain Res 179:3-20.

Schuett S, Bonhoeffer T, Hübener M (2002) Mapping retinotopic structure in mouse visual cortex with optical imaging. J Neurosci 22:6549-6559.

Seltzer B, Pandya DN (1978) Afferent cortical connections and architectonics of the superior temporal sulcus and surrounding cortex in the rhesus monkey. Brain Res 149:1-24.

Shao Z, Burkhalter A (1996) Different balance of excitation and inhibition in forward and feedback circuits of rat visual cortex. J Neurosci 16:7353-7365.

Sherman SM, Guillery RW (1998) On the actions that one nerve cell can have on another: distinguishing "drivers" from "modulators." Proc Natl Acad Sci U S A 95:7121-7126.

Sherman SM, Guillery RW (2006) Exploring the thalamus and its role in cortical function. Cambridge, MA: Massachusetts Institute of Technology.

Shipp S, Zeki S (1989) The organization of connections between areas V5 and V2 in macaque monkey visual cortex. Eur J Neurosci 1:333-354.

Simmons PA, Lemmon V, Pearlman AL (1982) Afferent and efferent connections of the striate and extrastriate visual cortex of the normal and reeler mouse. J Comp Neurol 211:295-308.

Thomson AM (2000) Molecular frequency filters at central synapses. Prog Neurobiol 62:159-196.

Thomson AM, West DC (1993) Fluctuations in pyramid-pyramid excit- 
atory postsynaptic potentials modified by presynaptic firing pattern and postsynaptic membrane potential using paired intracellular recordings in rat neocortex. Neuroscience 54:329-346.

Veinante P, Lavallée P, Deschênes M (2000) Corticothalamic projections from layer 5 of the vibrissal barrel cortex in the rat. J Comp Neurol 424:197-204.

Viaene AN, Petrof I, Sherman SM (2011a) Synaptic properties of thalamic input to layers $2 / 3$ in primary somatosensory and auditory cortices. J Neurophysiol 105:279-292.

Viaene AN, Petrof I, Sherman SM (2011b) Synaptic properties of thalamic input to the subgranular layers of primary somatosensory and auditory cortices in the mouse. J Neurosci 31:12738-12747.

Wang Q, Burkhalter A (2007) Area map of mouse visual cortex. J Comp Neurol 502:339-357.

Wu CW, Kaas JH (2003) Somatosensory cortex of prosimian Galagos: physiological recording, cytoarchitecture, and corticocortical connections of anterior parietal cortex and cortex of the lateral sulcus. J Comp Neurol 457:263-292.

Wu J, Rush A, Rowan MJ, Anwyl R (2001) NMDA receptor- and metabotropic glutamate receptor-dependent synaptic plasticity induced by high frequency stimulation in the rat dentate gyrus in vitro. J Physiol 533:745-755.

Wu J, Harney S, Rowan MJ, Anwyl R (2008) Involvement of group I mGluRs in LTP induced by strong high frequency stimulation in the dentate gyrus in vitro. Neurosci Lett 436:235-238.

Zeki S (1980) A direct projeciton from area V1 to area V3A of rhesus monkey visual cortex. Proc R Soc Lond B Biol Sci 207:499-506.

Zeki SM (1976) The projections to the superior temporal sulcus from areas 17 and 18 in the rhesus monkey. Proc R Soc Lond B Biol Sci 193:199-207.

Zeki SM, Sandeman DR (1976) Combined anatomical and electrophysiological studies on the boundary between the second and third visual areas of rhesus monkey cortex. Proc R Soc Lond B Biol Sci 194:555-562. 